\title{
'Steel' university tops the ratings in South Korea
}

Seoul. South Korea's new Pohang University of Science and Technology (POSTECH) has come top in the country's first attempt to rank its universities. POSTECH is supported by one of the world's most profitable steel companies, Pohang Iron and Steel Company (POSCO).

The ranking was made on the basis of various factors related to teaching and research. On most of these POSTECH came out ahead of the Seoul National University (SNU), which has traditionally been considered South Korea's best university. The survey of 131 universities was carried out at the end of last month by the Joong-ang Daily News, a leading national newspaper. It was followed a week later by a similar government report to the National Assembly.

But both analyses have one glaring omission, namely the exclusion of the Korea Advanced Institute of Science and Technology (KAIST), another top-ranking institution. Unlike the other universities, which come under the Ministry of Education, KAIST belongs to the Ministry of Science and Technology (MOST). As such, it is considered an outsider by other universities and the education ministry.

POSTECH came out top because of a low student/faculty ratio (6.4 to one, about a third that of SNU), a large budget for research and education (a significant portion of which comes from POSCO), a wellequipped library and laboratories and a large amount of floor space.

SNU has more publications cited in the Science Citation Index (SCI) of the US Institute for Scientific Information than POSTECH. But POSTECH's president, Sooyoung Chang, points out that the average number of SCI publications per faculty member in his institution is higher than that at SNU.

SNU leads the newspaper survey in terms of the number of graduates who have passed national examinations for professions such as the civil service, law and accounting, or who are chief executives of companies. P O T E C H does not appear near the top in these categories. But it has been in existence for only eight years and does not cover all the subject areas of the national examinations.
KAIST, which is located in Taeduck science town in central South Korea, would rank at or near the top in many of the categories in the survey. Since the beginning of 1992, for example, its researchers have produced almost a quarter of all South Korean publications listed in the SCI.

It also has a similar annual budget to POSTECH (US\$60 million). The US Accreditation Board for Engineering and Technology reported in an external review of the university in 1992 that KAIST had the potential to become "one of the top institutions in the world" (see Nature 364, 379; 1993).

KunMo Chung, president of the Institute for Advanced Engineering and a former minister of science and technology, says that KAIST was probably omitted from the survey to avoid embarrassing SNU. There has been rivalry between the two universities ever since KAIST was established by MOST in 1971 as South Korea's first graduate university. The decision was made over the objections of both SNU and the education ministry, which had wanted to strengthen graduate education at SNU.

Sang Chul Shim, the president of KAIST, says he is not surprised by the absence of his university from the ranking exercise - he is often not invited to official meetings of South Korea's university presidents.

But whatever the reason for KAIST's exclusion, it underlines a sharp division between MOST and the Ministry of Education over the administration of research. KAIST receives generous financial support from the government through MOST, while most South Korean universities are starved of government funds.

POSTECH is an exception because of the generous support it receives from POSCO. The company provides about half of the university's research and development funds in the form of grants for project research and also supplied most of the construction costs of the university (see Nature $364,380 ; 1993)$.

David Swinbanks

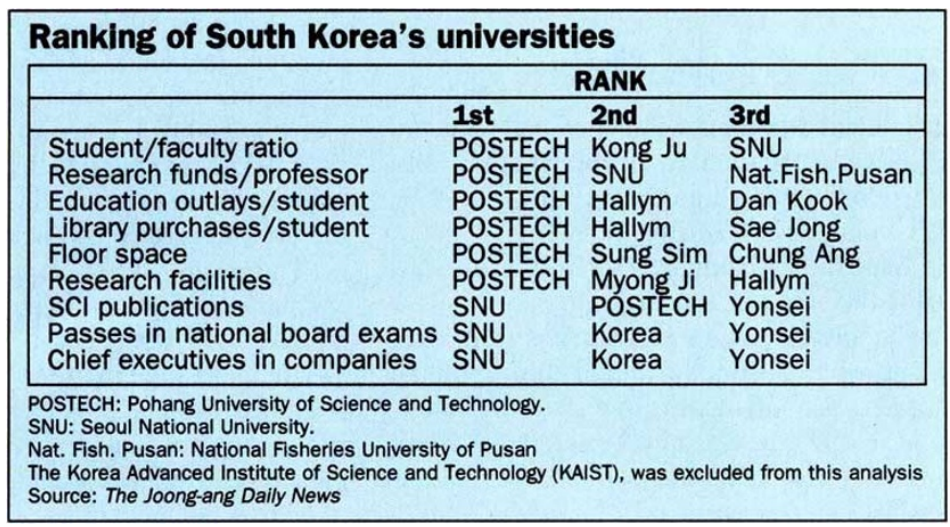

\section{HIV vaccines get the green light for Third World trials}

Geneva. An advisory committee to the World Health Organization (WHO) has recommended that large-scale Phase III trials of HIV vaccines should be allowed to proceed in developing countries. The decision was made even though the United States has not given permission for the trials of two such candidate vaccines, made from genetically engineered forms of HIV's envelope protein, primarily because of doubts over their effectiveness.

The recommendation was made at a meeting in Geneva last week of 40 scientists, public-health experts and others concerned with the growing spread of AIDS in developing countries. Under normal circumstances, WHO would be reluctant to support trials elsewhere of a vaccine that had not passed safety trials in its country of origin.

In the current situation, however, the advisory group eventually agreed that the different conditions prevailing in many developing countries justified its recommendation to proceed with the trials. But it also emphasized that "there must be no ethical or scientific short cuts to speed the process", and that the trials must be approved by the appropriate national authorities.

Even though the decision was unanimous, several individual committee members are believed to have reservations about the outcome. Their concern was focused on the possibility that the trials could unfairly raise expectations of success, and in some cases fears that vaccines could actually enhance disease in those who might later become infected. But others argued that even a vaccine with a relatively low level of efficacy might save large numbers of lives.

A key candidate country for future experiments is Thailand, where the US Department of Defense is thought to be planning trials of a recombinant gp120 vaccine - one of the two vaccines under consideration for trials in the United States - in collaboration with the US company Biocine. Genetech is also planning trials of its own recombinant gp 120 vaccine in a Third World country, but no definite plans have yet been announced by either company.

In a joint statement issued at the end of the meeting, the participants said that, although the scientific considerations for commencement of HIV efficacy trials should be the same in all parts of the world, "it is recognized that public health needs, as well as feasibility considerations, may be different from one country to another".

As a result, the group says, an analysis of the various types of considerations that should be made in relation to trials with specific candidate vaccines "may result in different recommendations in relation to efficacy trials in different parts of the world". 